\title{
The effects of glucose-dependent insulinotropic polypeptide infused at physiological concentrations in normal subjects and Type 2 (non-insulin-dependent) diabetic patients on glucose tolerance and B-cell secretion
}

\author{
I. R.Jones ${ }^{1}$, D. R. Owens ${ }^{1}$, A.J.Moody ${ }^{2}$, S. D. Luzio ${ }^{1}$, T.Morris ${ }^{1}$ and T. M.Hayes ${ }^{1}$ \\ ${ }^{1}$ Department of Medicine, University of Wales College of Medicine, Cardiff, Wales, UK and \\ ${ }^{2}$ Novo Research Institute, Bagsvaerd, Copenhagen, Denmark
}

\begin{abstract}
Summary. The effects of porcine glucose-dependent insulinotropic polypeptide given by continuous intravenous infusion in normal subjects $(n=6)$ and Type 2 (non-insulin-dependent) diabetic patients $(n=6)$ have been investigated. The subjects were studied on 2 separate days after overnight fasts. On each day $25 \mathrm{~g}$ of glucose was infused from $0-30 \mathrm{~min}$ plus an infusion of either porcine glucose-dependent insulinotropic polypeptide $\left(0.75 \mathrm{pmol} \cdot \mathrm{kg}^{-1} \cdot \mathrm{min}^{-1}\right)$ or control solution. During the glucose-dependent insulinotropic polypeptide infusion plasma glucose values were reduced in normal subjects from $30-60 \mathrm{~min}(p<0.01)$ and in Type 2 diabetic patients at 45 and $60 \mathrm{~min}(p<0.05)$. In the normal subjects insulin concentrations were greater from $10-35 \mathrm{~min}(p<$ 0.01 ) following glucose-dependent insulinotropic polypeptide infusion and peak values were increased by $123 \%$. In the Type 2 diabetic patients following glucose-dependent insulinotropic polypeptide infusion insulin levels were increased from 4-40 min $(p<0.01)$ but peak values were only increased by $27 \%$. In the normal subjects $\mathrm{C}$-peptide values
\end{abstract}

were greater from $25-45 \min (p<0.01)$ following glucosedependent insulinotropic polypeptide infusion and peak C-peptide levels were increased by $82 \%$. In the Type 2 diabetic patients following the glucose-dependent insulinotropic polypeptide infusion C-peptide levels were increased from 6-55 min $(p<0.01)$ and peak values were increased by $20 \%$. Plasma glucose-dependent insulinotropic polypeptide levels were within the physiological post prandial range during the glucose-dependent insulinotropic polypeptide infusion. Glucose-dependent insulinotropic polypeptide is insulinotropic in normal subjects and Type 2 diabetic patients at physiological concentrations and results in improved glucose tolerance. This insulinotropic effect is less marked in the diabetic patients and may represent insensitivity of the B cell to glucosedependent insulinotropic polypeptide.

Key words: Glucose, insulin, C-peptide, glucose dependent insulinotropic polypeptide, normal subjects, Type 2 diabetic patients.
A much greater insulin response is evoked in response to an oral glucose load compared with an equivalent amount administered intravenously, despite a much smaller increase in the blood glucose level with the former $[1,2]$. A significant proportion of the insulin secreted following an oral glucose load is dependent upon gastrointestinal factors [3-5]. The enteric hormone glucose dependent insulinotropic polypeptide (GIP) is secreted by $\mathrm{K}$ cells situated in the upper small intestine in response to oral but not intravenous glucose [6]. Recently a high-affinity GIP receptor has been demonstrated in a hamster pancreatic B-cell line [7] which is functionally linked to cAMP production [8]. Intravenous GIP infusions have been shown to potentiate the release of insulin in the presence of hyperglycaemia in normal subjects when infused at supraphysiological dosage levels $[9,10]$. An insulinotropic effect at physiological concentrations has also been demonstrated [11] but it was concluded that the effect of GIP was likely to be weak in individuals with normal glucose tolerance.

Recognition that GIP participates in the enteroinsular axis prompted investigations into its role in the pathophysiology of diabetes mellitus. Both increased and decreased GIP concentrations have been described in response to glucose, mixed meal and fat stimulation in diabetes mellitus [12-20]. Despite this large series of studies which have measured GIP concentrations in response to various stimuli, limited data is available regarding the effects of an intravenous infusion of GIP in diabetes mellitus [21, 22].

The aim of this study therefore was to investigate the metabolic responses to porcine GIP infused intravenously at a dose level which produced physiological concentrations of GIP in both normal subjects and newly diagnosed, untreated Type 2 diabetic patients. 


\section{Subjects and methods}

The studies were performed on 12 subjects consisting of 6 healthy male volunteers, with body mass indexes (BMI's) between 20-28, aged 24-34 years with no family history of diabetes; and 6 newly diagnosed previously untreated Type 2 diabetic patients with BMI's between 24-34, and aged 42-64 years. The Type 2 diabetic patients all had raised fasting plasma glucose levels (Fig. 2), increased $\mathrm{HbA}_{1}$ concentrations (10.6-14.2\%) and were all non-ketotic (the normal range of the $\mathrm{HbA}_{1}$ assay is $5.9-7.9 \%$ ). All subjects were studied on 2 separate days at intervals of 1 week, during which they received an intravenous infusion of glucose (IVGTT) either with or without a concomitant infusion of porcine GIP in random order. The study was approved by the local ethical committee and informed consent was given by each subject.

After a 10 -h overnight fast the subjects were admitted to a metabolic unit, where they remained on bed rest throughout the study; smoking was not permitted. An intravenous cannula (Venflon 19G) was inserted into an antecubital vein and attached via a three-way tap to a slow running infusion of saline $(0.154 \mathrm{mmol} / 1)$. All blood samples were taken from this cannula, and at each of the sampling time points the saline infusion was stopped and $2 \mathrm{ml}$ of blood was withdrawn and discarded prior to obtaining the sample for subsequent analysis. A similar cannula was inserted in the contralateral arm and this was used for the infusion of glucose and GIP. The IVGTT was performed by infusing $25 \mathrm{~g}$ of glucose $(50 \mathrm{ml} 50 \%$ dextrose) from 0-30 min. Porcine GIP was isolated from an acid alcohol extract of porcine small intestine by ion-exchange chromatography followed by a final purification on HPLC. The identity of the peptide was confirmed by determining its amino acid sequence [23]. The preparation used in the present study was screened for unexpected side effects in an acute toxicological study and its efficacy as an insulin releasing agent demonstrated in the pig [24]. Purified porcine GIP (Novo Research Institute, Copenhagen, Denmark) which had been sterile filtered and lyophilised with human serum albumin was dissolved in $50 \mathrm{ml}$ Haemaccel (Hoechst AG, Frankfurt, FRG) to reduce adsorption to the giving set. The GIP was infused using a syringe pump and a $50 \mathrm{~cm}$ manometer line which had been flushed with the GIP solution for 10 min prior to being connected to the subjects via the cannula. GIP was infused intravenously from $0-30 \mathrm{~min}$ at a dose of $0.75 \mathrm{pmol} \cdot \mathrm{kg}^{-1} \cdot \mathrm{min}^{-1}$. During a control study a similar volume of Haemaccel was infused from 0-30 min.

Blood samples were taken at 08.30 hours and immediately prior to the infusions at 09.00 hours. Samples were then taken at 2-min intervals for $10 \mathrm{~min}$ then every $5 \mathrm{~min}$ for $60 \mathrm{~min}$, with further samples taken at 90 and $120 \mathrm{~min}$. At each time point plasma glucose, C-peptide, immunoreactive insulin (IRI) and GIP concentrations were measured.

The blood was taken into fluoride for plasma glucose determination (glucose oxidase) and into lithium-heparin tubes containing 1000 kallibrein inhibitory units (KIU) of aprotinin (Novo A/S, Bagsvaerd, Denmark) for the determination of C-peptide [25], insulin [26] and GIP levels [27]. All samples were collected on ice, centrifuged immediately at $4{ }^{\circ} \mathrm{C}$ and the plasma stored at $-20^{\circ} \mathrm{C}$ until assay. The detection limit of IRI was $0.022 \mathrm{nmol} / 1$ and the precision (SD within assay) was $0.009 \mathrm{nmol} / \mathrm{l}$. The detection limit for C-peptide was $0.035 \mathrm{nmol} / 1$ and the precision $0.0115 \mathrm{nmol} / 1$. The sequence of porcine GIP differs from human GIP at residues 18 and 24 [28]. The antiserum used in this study does not, however, discriminate between human and porcine GIP since the sequence recognised by the antiserum is identical in both molecules [23]. The GIP detection limit was $5 \mathrm{pmol} / 1$ and the precision $1.7 \mathrm{pmol} / 1$.

\section{Statistical analysis}

The results are expressed as means $\pm \mathrm{SE}$ and the significance of differences assessed using the Student's paired t-test. A $p$ value of $<0.05$ was considered statistically significant.

\section{Results}

The mean venous plasma glucose, C-peptide, IRI and GIP concentrations for the normal subjects and the Type 2 diabetic patients are shown in Figure 1 and Figure 2 respectively.

In the normal subjects fasting plasma glucose levels were similar for both tests. During the IVGTT plasma glucose increased from a fasting level of $4.9 \pm 0.2$ to a peak of $9.9 \pm 0.2 \mathrm{mmol} / 1$ at $30 \mathrm{~min}$ and returned to basal levels by $90 \mathrm{~min}$. Following the intravenous infusion of glucose and GIP plasma glucose values increased from a fasting level of $4.9 \pm 0.2 \mathrm{mmol} / 1$ to a slightly lower peak of $9.3 \pm 0.3 \mathrm{mmol} / 1$ at $20 \mathrm{~min}$. Glucose levels then started to decline and were significantly lower following the IVGTT plus GIP infusion compared with the IVGTT alone from $35-60 \mathrm{~min}$ $(p<0.05-0.01)$. Glucose levels returned to fasting values earlier following the GIP infusion and reached fasting concentrations by $50 \mathrm{~min}$.

Following the IVGTT C-peptide levels increased from a fasting value of $0.49 \pm 0.04 \mathrm{nmol} / 1$ to a peak level of $1.8 \pm 0.2 \mathrm{nmol} / \mathrm{l}$ at $35 \mathrm{~min}$. During the GIP infusion C-peptide values increased from a similar fasting value of $0.48 \pm 0.04 \mathrm{nmol} / 1$ to a peak level of $3.28 \pm 0.35 \mathrm{nmol} / 1$ at $30 \mathrm{~min}$. C-peptide levels were significantly higher following the GIP infusion between 25 and $45 \mathrm{~min} .(p<0.05-0.01)$.

IRI levels showed a similar pattern increasing from a fasting value of $0.08 \pm 0.01 \mathrm{nmol} / 1$ to a peak of $0.34 \pm 0.04 \mathrm{nmol} / 1$ at $30 \mathrm{~min}$ during the IVGTT. Following the GIP infusion IRI levels increased from a similar fasting level of $0.07 \pm 0.01 \mathrm{nmol} / 1$ to a higher peak concentration of $0.76 \pm 0.05 \mathrm{nmol} / 1$ at $25 \mathrm{~min}$. During the GIP infusion IRI levels were significantly higher compared with the IVGTT alone from 10-35 $\min (p<0.05-0.01)$.

The mean fasting GIP concentrations were similar for both tests and, as expected did not alter during the IVGTT, ranging between $18.4 \pm 4.1$ and $24.6 \pm$ $5.2 \mathrm{pmol} / \mathrm{l}$. The GIP infusion increased plasma GIP concentrations from a fasting level of $19.8 \pm 4.0 \mathrm{pmol} / 1$ to a peak of $76 \pm 9.4 \mathrm{pmol} / \mathrm{l}$ at $30 \mathrm{~min}$ thereafter falling gradually although the concentration was still above fasting levels after $120 \mathrm{~min}$.

In the Type 2 diabetic patients fasting plasma glucose levels were elevated and similar for both tests. Following the IVGTT, plasma glucose increased from a fasting value of $9.2 \pm 0.2 \mathrm{mmol} / 1$ to a peak of $14.4 \pm$ $0.3 \mathrm{mmol} / 1$ at $35 \mathrm{~min}$. During the GIP infusion glucose increased from a fasting value of $8.9 \pm 0.2 \mathrm{mmol} / 1$ to a peak of $14.2 \pm 0.3 \mathrm{mmol} / 1$ at $35 \mathrm{~min}$. Glucose levels were significantly lower following the GIP infusion at 45 and $60 \mathrm{~min}(p<0.05)$.

Following the IVGTT, C-peptide levels increased from a fasting level of $0.97 \pm 0.05 \mathrm{nmol} / 1$ to a delayed peak value of $1.48 \pm 0.2 \mathrm{nmol} / \mathrm{l}$ at $50 \mathrm{~min}$. During the 

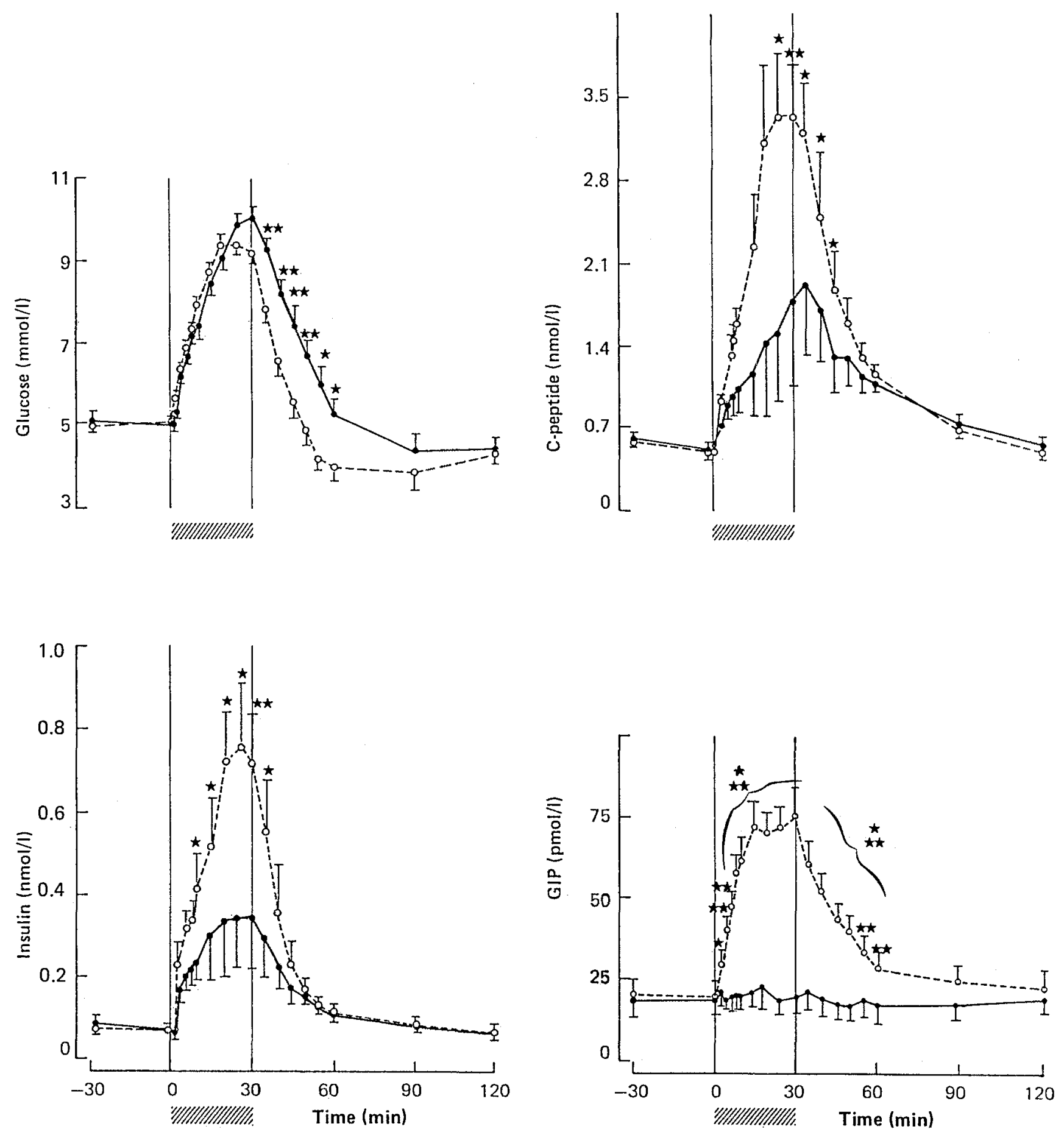

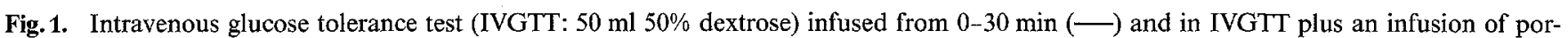
cine GIP $\left(0.75 \mathrm{pmol} \cdot \mathrm{kg}^{-1} \cdot \mathrm{min}^{-1}\right)$ from $0-30 \mathrm{~min}(---)$ in normal subjects $(n=6)$. Mean $\pm S E$ concentrations of plasma glucose, insulin, C-peptide and GIP. * $p<0.05 ; * * p<0.01 ; * * p<0.001$

GIP infusion C-peptide increased from a fasting value of $1.02 \pm 0.07 \mathrm{nmol} / 1$ to a peak level of $1.78 \pm$ $0.22 \mathrm{nmol} / 1$ at $35 \mathrm{~min}$. The C-peptide values were significantly greater following the GIP infusion from $6-55 \min (p<0.05-0.01)$.

IRI concentrations increased from a fasting value of $0.14 \pm 0.01 \mathrm{nmol} / 1$ to a peak of $0.26 \pm 0.03 \mathrm{nmol} / \mathrm{l}$ at $50 \mathrm{~min}$ following the IVGTT. During the GIP infusion IRI increased from a value of $0.15 \pm 0.01 \mathrm{nmol} / 1$ to an earlier peak of $0.33 \pm 0.03 \mathrm{nmol} / 1$ at $35 \mathrm{~min}$. The IRI concentrations were significantly higher following the GIP infusion from 4-40 min ( $p<0.05-0.01)$.

Fasting GIP levels were similar for both tests and did not change during the IVGTT and ranged from $17.2 \pm 4.1$ to $25.6 \pm 4.8 \mathrm{pmol} / 1$. Following the GIP infusion GIP levels increased from a fasting value of $12.5 \pm 5 \mathrm{pmol} / 1$ to a peak concentration of $104 \pm$ $9.6 \mathrm{pmol} / 1$ at $35 \mathrm{~min}$. 

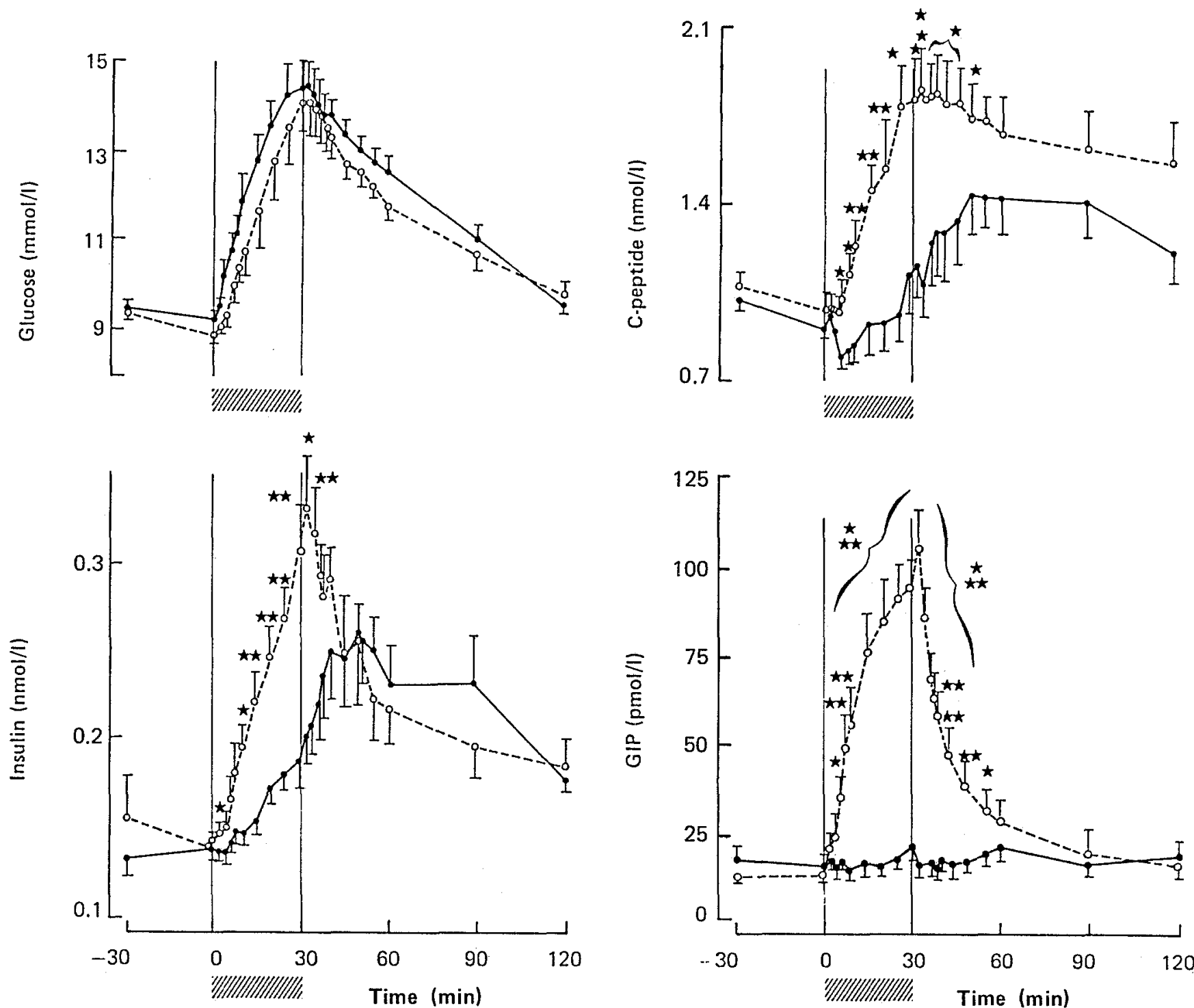

Fig. 2. Intravenous glucose tolerance test (IVGTT: $50 \mathrm{ml} \mathrm{50 \%} \mathrm{dextrose)} \mathrm{infused} \mathrm{from} 0-30 \mathrm{~min}(-)$ and an IVGTT plus an infusion of porcine GIP $\left(0.75 \mathrm{pmol} \cdot \mathrm{kg}^{-1} \cdot \mathrm{min}^{-1}\right)$ from $0-30 \mathrm{~min}(---)$ in Type 2 diabetic patients $(n=6)$. Mean \pm SE concentrations of plasma glucose, insulin, C-peptide and GIP. * $p<0.05 ; * * p<0.01 ; * * * 0001$

\section{Discussion}

This study clearly shows that intravenous infusion of highly purified porcine GIP, previously shown to be a strong potentiator of insulin release in the pig [24], potentiates B-cell secretion in response to intravenous glucose and results in improved glucose tolerance in both normal subjects and newly diagnosed Type 2 diabetic patients.

In the normal subjects the peak glucose values following a $25 \mathrm{~g}$ intravenous glucose load are similar to levels seen previously with oral glucose $(75 \mathrm{~g})$ or a standard test meal $(500 \mathrm{kcal})$ in normal subjects [29, 30]. Similarly the glucose response in the untreated Type 2 diabetic patients approximates to the range expected following an oral glucose tolerance test or meal test $[31,32]$. Following the GIP infusion in normal subjects there was a definite and highly significant im- provement in glucose tolerance with mean glucose concentrations returning to fasting levels earlier at $50 \mathrm{~min}$. In the diabetic patients the effect on glucose tolerance was less marked, with a trend for lower mean glucose values with the GIP infusion; the difference reaching significance at 45 and $60 \mathrm{~min}(p<0.05)$.

The improvement in glucose tolerance, particularly in the normal subjects, resulted from the considerable enhancement of B-cell secretion with the addition of GIP to the intravenous glucose infusion. In the normal subjects the addition of GIP resulted in a prompt increase in plasma insulin reaching a peak of $0.76 \mathrm{nmol} / 1$ which represents a $123 \%$ increase above the mean peak value seen after the intravenous glucose alone. Intravenously administered GIP in the normal subjects converted the insulin response seen during the IVGTT to that normally observed in response to either an oral glucose or meal tolerance test $[22,23]$. The in- 
sulin level was significantly elevated as early as $10 \mathrm{~min}$ after the commencement of the GIP infusion, continuing for a further $25 \mathrm{~min}$, falling $5 \mathrm{~min}$ after the cessation of GIP and intravenous glucose. A similar increase was observed in C-peptide concentrations with a prompt rise in C-peptide during the GIP infusion to a peak value $82 \%$ higher than that seen after glucose alone. These results support the earlier findings in pigs [24].

In the diabetic group there was a less marked but nevertheless significant improvement in B-cell secretory function following the infusion of GIP. From elevated basal insulin levels $(\sim 0.12 \mathrm{nmol} / 1)$ in the Type 2 diabetic patients a slow increase to a delayed peak of only $0.26 \mathrm{nmol} / 1$ at $50 \mathrm{~min}$ was seen following intravenous glucose. With the addition of GIP there was a more prompt increase in insulin levels, reaching a higher and earlier peak of $0.33 \mathrm{nmol} / 1$ at $35 \mathrm{~min}$. This represents a $27 \%$ increase above the peak level seen after the glucose alone compared with $123 \%$ in normal subjects. A similar pattern was observed in the C-peptide response, which increased more rapidly to an earlier peak of $1.78 \mathrm{nmol} / 1$ at $35 \mathrm{~min}$, representing a $20 \%$ increase above the maximum value achieved with the intravenous glucose. The smaller increase in insulin secretion and the fact that the diabetic group were probably more insulin resistant may account for the relatively small improvement in glucose tolerance in the Type 2 diabetic patients. These findings are consistent with those of Nauck et al. [33] who described a reduced incretin effect in Type 2 diabetic patients compared with normal control subjects. They estimated that the contribution of incretin factors to total insulin responses was $72.8 \pm 6.9 \%$ in control subjects and $36.0 \pm 8.8 \%$ in diabetic patients. Our results demonstrate that this difference in incretin response in Type 2 diabetic patients results mainly from a decreased response to GIP.

There are two possible explanations for this relatively small enhancement in B-cell function in response to an IVGTT by GIP in the diabetic group. Firstly B-cell function is clearly abnormal in this group with a rather slow rise in levels of insulin and C-peptide to markedly reduced peak concentrations, and it is possible that the relatively small enhancement in secretion produced by the GIP infusion represents the maximum secretory capacity of the damaged B cells.

We have recently presented data regarding the metabolic profiles in a group of Type 2 diabetic patients $(n=65)$ following oral glucose and meal tolerance tests [31]. The peak insulin response in a group of similar severity following the meal test was considerably higher than the control study with intravenous glucose alone $(0.57 \pm 0.4 \mathrm{nmol} / \mathrm{l})$ suggesting the $B$ cells in these patients should have further secretory potential. An alternative explanation for decreased insulin potentiation by GIP in the Type 2 diabetic patients is that there is decreased sensitivity of the B cells to the insulinotropic effect of GIP as suggested by Nauck et al. [33].

The GIP infusion rate in this study resulted in plasma GIP concentrations well within the post prandial range that one sees in both normal subjects and Type 2 diabetic patients $[31,32]$. Porcine GIP differs from human GIP with respect to its amino acid sequence [28]. The use of porcine GIP makes it difficult to assess plasma levels and to compare, in terms of biological activity, post prandial GIP responses to those during infusions by radioimmunoassay methods. Similar radioimmunoassay readings for post prandial (endogenous human) and post infusion (exogenous porcine) GIP do not necessarily imply identical plasma concentrations with identical biological activity. This problem should, however, be minimised as the antiserum (R65) used in this study does not discriminate between porcine and human GIP, since the sequence recognised by R65 is identical in both molecules [23]. The large increase in insulin secretion particularly in the normal subjects therefore resulted from a physiological increase in the plasma GIP concentration. This indicates that GIP may be the major incretin factor in the physiological state in man.

In conclusion we have shown that GIP is insulinotropic in both normal subjects and newly diagnosed Type 2 diabetic patients at physiological plasma concentrations and results in improved glucose tolerance, although the effect is less marked in the Type 2 diabetic patients.

\section{References}

1. McIntyre N, Holdsworth CD, Turner OS (1964) New interpretation of oral glucose tolerance. Lancet 2: 20-21

2. Brown JC, Otte SC (1978) Gastrointestinal hormones and the control of insulin secretion. Diabetes 27: 782-789

3. Katz A, Rubenstein AH (1973) Metabolism of proinsulin, insulin and C-peptide in the rat. J Clin Invest 5-12: 1113-1121

4. Hampton SM, Morgan LM, Tredger JA, Cramb R, Marks V (1986) Insulin and C-peptide levels after oral and intravenous glucose. Diabetes 35: 612-616

5. Nauck M, Homberger E, Siegel E, Allen R, Eaton R, Ebert R and Creutzfeldt W (1986) Incretin effects of increasing glucose loads in man calculated from venous insulin and C-peptide responses. J Clin Endocrinol Metab 63: 492-498

6. Cleator IGM, Gourlay RH (1975) Release of immunoreactive gastric inhibitory polypeptide (IR-GIP) by oral ingestion of food substances. Am J Surg 13: 128-135

7. Maletti M, Portha B, Carlquist M, Kergoat M, Laburthe M, Marie JC, Rosselin G (1984) Evidence for and characterisation of specific high affinity binding sites for the gastric inhibitory polypeptide in pancreatic beta cells. Endocrinology 115: 1324-1331

8. Amiranoff B, Vanclin-Jacques N, Labenthe M (1984) Functional GIP receptors in a hamster pancreatic-cell line. In: III: Specific binding and biological effects. Biochem Biophys Res Commun 123: 671-676

9. Dupre J, Ross SA, Watson D and Brown JC (1973) Stimulation of insulin secretion by gastric inhibitory polypeptide in man. $J$ Clin Endocrinol Metab 37: 826-828 
10. Elahi D, Andersen DK, Brown JC, Debas HT, Hershcopf RJ, Raizes GS, Tobin JD and Andres R (1976) Pancreatic alpha and beta cell responses to GIP infusion in normal man. Am J Physiol 237: E 185-191

11. Sarson DL, Wood SM, Holder D, Bloom SR (1982) The effect of glucose dependent insulinotropic polypeptide infused at physiological concentrations of the release of insulin in man. Diabetologia 22: 33-36

12. Brown JC, Dryburgh JR, Ross SE, Dupre J (1975) Identification and actions of gastric inhibitory polypeptide. Recent Prog Horm Res 31: 487-532

13. Crockett SE, Mazzaferri EL, Cataland S (1976) Gastric inhibitory polypeptide (GIP) in maturity onset diabetes mellitus. Diabetes 25: 931-935

14. Ebert R, Frerichs H, Creutzfeldt W (1976) Serum gastric inhibitory polypeptide responses in patients with maturity onset diabetes and in juvenile diabetics. Diabetologia 12: 388 (Abstract)

15. Ross SA, Brown JC, Dupre J (1977) Hypersecretion of gastric inhibitory polypeptide following oral glucose in diabetes mellitus. Diabetes 26: 525-529

16. Bloom SR (1975) GIP in diabetes. Diabetologia 2: 334 (Abstract)

17. Alam MJ, Buchanan KD (1980) Gastric inhibitory polypeptide (GIP) responses in primary diabetes. Regul Pept 1 [Suppl]: 52 (Abstract)

18. Krarup T, Madsbad S, Moody AJ, Regeur O, Faber K, Holst JJ and Sestoft L (1983) Diminished immunoreactive gastric inhibitory polypeptide response to a meal in newly diagnosed Type 1 (insulin dependent) diabetics. J Clin Endocrinol Metab 56: 1306-1312

19. Coxe JS, O'Dorisio TM, Cataland S, Crockett SE (1981) Gastric inhibitory polypeptide hypersecretion in diabetes mellitus. Effect of sulphonylurea treatment. J Clin Endocrinol Metab 52: $1002-1005$

20. Salera M, Giacomoni P, Pironi L, Cornia G, Capelli M, Marini A, Benfenati F, Miglioli M, Barbara L (1982) Gastric inhibitory polypeptide release after oral glucose: relationship to glucose intolerance, diabetes mellitus and obesity. J Clin Endocrinol Metab 55: 329-336

21. Ross SA, Dupre J (1978) Effects of ingestion of triglyceride or galactose on secretion of gastric inhibitory polypeptide and on responses to intravenous glucose in normal and diabetic subjects. Diabetes 27: $327-333$

22. Amland PF, Jorde R, Aanderud P, Burhol PG, Giercksky KE (1985) Effects of intravenously infused porcine GIP on serum insulin, plasma C-peptide, and pancreatic polypeptide in non-insu- lin-dependent diabetes in the fasting state. Scand $\mathbf{J}$ Gastroenterol 20:315-320

23. Moody AJ, Jorgensen KD, Thim L (1981) Structure function relationship in porcine GIP. Diabetologia 21: 306 (Abstract)

24. Wolffbrandt KH, Damm Jorgensen K, Moody AJ, Pedersen PC (1986) The effects porcine GIP on insulin secretion and glucose clearance in the pig. Horm Metabol Res 18: 159-162

25. Heding LG (1975) Radioimmunological determination of human C-peptide in serum. Diabetologia 11: 541-548

26. Heding LG (1972) Determination of total serum insulin (IRI) in insulin treated diabetic patients. Diabetologia 8: 260-266

27. Lauritsen KB, Moody AJ (1978) The response of gastric inhibitory polypeptide (GIP) and insulin to glucose in duodenal ulcer patients. Diabetologia 14: 149-153

28. Moody AJ, Thim L, Valverde I (1984) The isolation and sequencing of human gastric inhibitory polypeptide (GIP). FEBS Lett 172: 142-148

29. Service FJ, Hall LD, Westland RE, O'Brien PC, Go VLW, Hay. mond MW, Rizza RA (1983) Effects of size, time of day and sequence of meal ingestion on carbohydrate tolerance in normal subjects. Diabetologia 25: 316-321

30. Grapo PA, Reaven G, Olefsky J (1976) Plasma glucose and insulin responses to orally administered simple and complex carbo. hydrates. Diabetes 25: 741-747

31. Jones IR, Owens DR, Birtwell AJ, Luzio SD, Davies CJ, Hayes TM (1984) Hormonal and metabolic responses to glucose and meal tests in NIDDM patients. Diabetic Med 2: 163 (Abstract)

32. Jones IR, Owens DR, Luzio SD, Hayes TM (1986) Glucose dependent insulinotropic polypeptide (GIP) concentrations in noninsulin dependent diabetes mellitus. Diabetic Med 3: 557 (Abstract)

33. Nauck M, Stockmann F, Ebert R, Creutzfeldt W (1969) Reduced incretin effect in Type 2 (non-insulin dependent) diabetes. Diabetologia 29: 46-52 (Abstract)

Received: 13 August 1986

and in revised form: 16 July 1987

Dr. I. R. Jones

Department of Medicine, Ward 10 Office

Royal Victoria Infirmary

Newcastle upon Tyne NE1 4LP

UK 